\title{
The corrosion influencing factors and its mechanism of N80 carbon steel in NaCl-NaHCO 3 solution
}

\author{
Gang Xie, Juan Xie, Haijun Yan, Qingzhen Du, Shuangyan Zhang, \\ Wei Zhang, Zhonghai Qin, Li Han, Wei Meng \\ Petroleum Production Engineering Research Institute of Huabei Oilfield Company \\ Renqiu Hebei, P R of China
}

\begin{abstract}
The N80 steel corrosion behavior of the produced water in Huabei oil field on behalf of $\mathrm{NaCl} / \mathrm{NaHCO}_{3}$ solution were studied by the corrosion weight loss method, and the fitted chart board involved salinity and anion content was built based on the least squares principle. Results show that influenced by $\mathrm{Cl}^{-}$and $\mathrm{HCO}_{3}{ }^{-}$control the corrosion curve involves three parts: passivating area, activated area and high corrosion area. The corrosion behavior shows that the area when $\mathrm{Cl}^{-} \%$ content in 16.7 37.5\% was $\mathrm{HCO}_{3}{ }^{-}$passivating control; in $37.05 \sim 90.9 \%$ was $\mathrm{HCO}_{3}{ }^{-}$and $\mathrm{Cl}^{-}$coordinated control; in $90.9 \sim 100 \%$ belong to $\mathrm{Cl}^{-}$perforation control. The fitted chart board considered water salinity and anion content could determine whether the corrosion occur or not, thus may provide theoretical foundation and guidance for the next support design of anticorrosion measures with carbon steel.
\end{abstract}

Keyword- $\mathrm{Cl}^{-} / \mathrm{HCO}_{3}^{-}$system; N80 carbon steel; corrosion behavior; chart board

\section{INTRODUCTION}

For the oil well formation water is an essential part in produced fluid, of which the corrosive medium consist high concentration of chloride ion, HCO3-, CO2, dissolved oxygen and other gases. The mild steel characteristics of polarization curve and surface oxides at various NaHCO3 solution were both studied, thus often lead to severe pitting behavior particularly in solutions contain high concentration of $\mathrm{HCO}_{3}{ }^{-}, \mathrm{Cl}^{-}$and $\mathrm{Ca}^{2+}$ (Jing-mao Zhao et al.[1] ; Mao et al. [2]) . The typical water type of formation water and injected water in Huabei Oilfield are $\mathrm{CaCl}_{2}$ by high salinity and $\mathrm{NaHCO}_{3}$ as surface water ${ }^{[3]}$. With the waterflooding development due to the mix by injected water, formation water have been gradually diluted, and the properties of produced fluid would change to some degree, such as decrease of $\mathrm{HCO}_{3}{ }^{-}$but rising $\mathrm{Cl}^{-[4]}$. For example according to statistics, since development the mole ratio $\mathrm{Cl}^{-} / \mathrm{HCO}_{3}^{-}$in produced fluid of some typical wells have dropped from the original 60 70 to 10 20 currently.

N80 steel pipe has been widely used in the oil and gas industry which accounted for over $50 \%$ of the total casing. Due to varieties of corrosive medium in produced fluid, the surface of N80 steel often suffered serious corrosion represented by casing damage and corrosion perforation, and such accidents that seriously affect the economic benefits of oil field. Therefore it is important to study local corrosion rules with influencing factors in $\mathrm{NaCl} / \mathrm{NaHCO}_{3}$ system, thus provide effective technical way and steps for further corrosion control and safety production in oil fields.

\section{EXPERIMENTAL}

\subsection{Material and solution}

The commercial carbon steel N80 was provided by Baoshan Iron \& steel Co. Ltd, with compositions as listed in Table I. The test couples were machined to a size of $50 \mathrm{~mm} \times 25 \mathrm{~mm} \times 3 \mathrm{~mm}$. Prior to the experiments the surfaces of the specimens were ground with silicon carbide $(\mathrm{SiC})$ papers progressively up to 600 grit rinsed with distilled water and then degreased in acetone. After drying in hot air the specimens were weighed (precision $0.1 \mathrm{mg}$ ) and then stored in a desicator for use.

All corrosion experiments were carried out in a high temperature and high pressure autoclave(OFITE company, USA). The corrosion medium was $\mathrm{NaCl}$ and $\mathrm{NaHCO}_{3}$ solution as simulating the formation water in oil field. The test conditions are shown in Table II chosen by produced water analysis in huabei oilfield. Prior to the experiments, the solution was purged with purified $\mathrm{N}_{2}$ to deoxidize for $2 \mathrm{~h}$ and then introduced into the autoclave.

TABLE I CHEMICAL COMPOSITIONS OF N80 CARBON STEEL（WT\%）

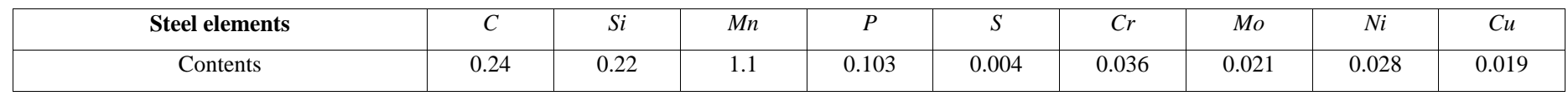


TABLE II TEST CONDITIONS

\begin{tabular}{|c|c|c|c|c|}
\hline Test duration $(\mathbf{h})$ & Temperature $\left({ }^{\circ} \mathrm{C}\right)$ & Pressure $(\mathrm{MPa})$ & Total salinity $(\mathrm{g} / \mathrm{L})$ & $\mathrm{Cl}^{\mathrm{l}} / \mathrm{HCO}{ }^{-}(\mathrm{mole} \mathrm{ratio})$ \\
\hline 72 & 70 & Normal & $10 \sim 100$ & $10 \sim 50: 1$ \\
\hline
\end{tabular}

\subsection{Weight loss tests}

According to industrial criterion "water corrosion test method"(China SY/T 00210-1999), the corrosion rate was measured by static corrosion weight-loss methods. Weight loss tests were conducted in a $10 \mathrm{~L}$ autoclave to investigate corrosion rate in simulated formation water. After the experiments, all specimens were taken out and immediately cleaned by distilled water and acetone. To remove the corrosion product scale, the specimens were bathed in $2 \%$ hydrochloric acid (HCl) inhibited with $10 \mathrm{~g} / \mathrm{L}$ hexamethylenetetramine (urotropine) at room temperature, and then rinsed and dried. After that, the samples were weighed again to obtain the final weight. The weight loss of the specimen was determined and the corrosion rate was calculated by the following equation:

$$
V_{\text {corr }}=\frac{8.76 \times 10^{4} \Delta m}{S \rho t}
$$

Where $\mathrm{V}_{\text {corr }}$ is the corrosion rate, $\mathrm{mm} / \mathrm{y} ; \Delta \mathrm{m}$ is the weight loss, $g ; \quad S$ is the surface area of specimen, $\mathrm{cm}^{2} ; \rho$ is the density of test steels, $\mathrm{g} / \mathrm{cm}^{3} ; \mathrm{t}$ is the immersion time, h. The final value of the corrosion rate in this study was averaged from two individual measurements after $72 \mathrm{~h}$ corrosion tests.

\section{RESULTS AND DISCUSSION}

\subsection{The influence of $\mathrm{Cl}^{-}$on corrosion rate}

Considered by its smaller radius (ion radius was only $\left.1.81 \times 10^{-10} \mathrm{~m}\right), \mathrm{Cl}^{-}$anion was easy to penetrate into the protective film which resulted in local corrosion, even in the anode zone high concentration of $\mathrm{Cl}^{-}$lead to spread of the pitting corrosion, thus early research has shown that $\mathrm{Cl}^{-}$ anion is one of the most influencing factors in carbon steel corrosion $^{[5]}$.

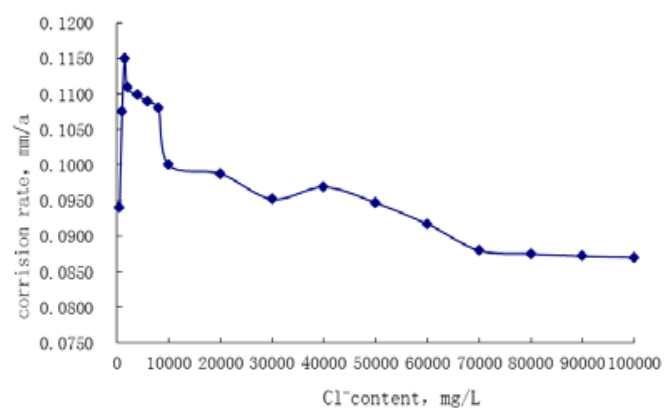

Fig.1 The influence of $\mathrm{Cl}^{-}$on corrosion rate
Figure 1 showed corrosion rate curve of N80 steel in $\mathrm{NaCl}$ solution. It was found that steel surface was black, and after cleaning it become smooth even white without pitting. The corrosion rate was low when $\mathrm{Cl}^{-}$content was $500 \mathrm{mg} / \mathrm{L}$, but in concentration between $500 \sim 10000 \mathrm{mg} / \mathrm{L}$ corrosion rate increased significantly ( average reached to 0.1100 $\mathrm{mm} / \mathrm{a})$.Then continued to add $\mathrm{NaCl}$ corrosion rate decreased to a certain value. It is worth noting that while salt concentration exceeded to certain range, the solution activity of $\mathrm{H}^{+}$cation was increased which drove the metal state turned from passivation state to active state, that is to say the accelerated dissolution rate raised up the anodic corrosion reaction ; when the $\mathrm{Cl}^{-}$concentration was above 10000 $\mathrm{mg} / \mathrm{L}$, due to the decreased solution conductivity and strong anion adsorption the corrosion rate was comparatively reduced as previous study showed excessive $\mathrm{Cl}^{-}$anion may adsorb on the membrane surface and generate $[\mathrm{FeCl}(\mathrm{OH})]^{-}$.

\subsection{The influence of $\mathrm{HCO}_{3}{ }^{-}$on corrosion rate}

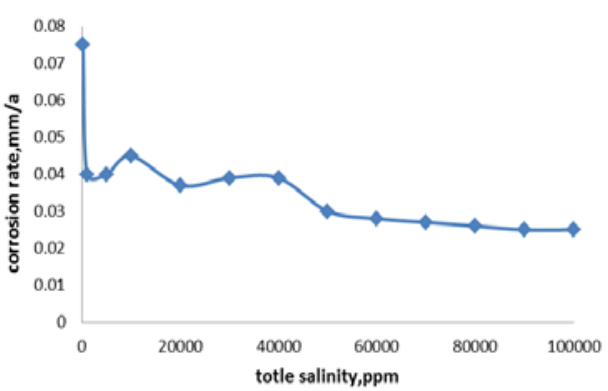

Fig.2 The influence of HCO3- on corrosion rate

As shown in figure 2 the critical concentration of HCO3lied at $0.02 \mathrm{~mol} / \mathrm{L}$. Under that HCO3- anion had a strong corrosive to carbon steel as higher corrosion rate ; when above $0.02 \mathrm{~mol} / \mathrm{L}$, corrosion rate dropped by degrees as the passivation film on steel surface was formed. Agreed with the similar reports by Jing-mao Zhao ${ }^{[6]}$, and Z. $\mathrm{Xia}^{[7]}$, the $\mathrm{H}_{2} \mathrm{O}$ reduction reacted in cathode at low concentration of $\mathrm{HCO}_{3}^{-}$, however at high concentration particularly in $\mathrm{CO}_{2}$ saturated salt solution a solid layer of $\mathrm{Fe}\left(\mathrm{CO}_{3}\right)_{2}$ membrane was formed on metal surface, thus had protective effect on carbon steel.

\subsection{The influence of $\mathrm{Cl}^{-} / \mathrm{HCO}_{3}{ }^{-}$on corrosion rate}

(1)Experimental analysis

The properties of corrosion products and corrosion rate were shown in Tab.III and Fig.3. It was found that mole ratio $\mathrm{Cl}^{-} / \mathrm{HCO}_{3}{ }^{-}$presented corrosion behavior as follows: (1) when the $\mathrm{Cl}^{-}$content and salinity lied in $16.7 \sim 90.9 \%$ and $10000 \sim 100000 \mathrm{mg} / \mathrm{L}$ respectively, the corrosion rate was 
only $0.033 \mathrm{~mm} / \mathrm{a}$, especially among $16.7 \sim 37.5 \%$ the generated passivating membrane on steel surface prevented the corrosion reaction because of the protective $\mathrm{HCO}_{3}^{-}$anion. Continue to add $\mathrm{Cl}^{-}$the corrosion rate increased slightly which indicated local activation of the steel was caused and passivation film was destroyed step by step. (2) when the concentration of $\mathrm{Cl}^{-}$ion was between $90.9 \sim 100 \%$ the corrosion rate grew up exponentially, and mainly corrosion products were $\mathrm{Fe}(\mathrm{OH})_{2}$ at low salinity $(10 \sim 20 \mathrm{~g} / \mathrm{L})$.

TABLE III THE PROPERTIES OF CORROSION PRODUCTS

\begin{tabular}{|c|c|c|c|c|c|}
\hline $\begin{array}{l}\text { Total } \\
\text { salinity }(10 \mathrm{~g} / \mathrm{L})\end{array}$ & $\mathrm{Cl}^{-}$content(\%) & Carbon Steel description & $\begin{array}{l}\text { The properties of corrosion } \\
\text { products }\end{array}$ & Preliminary analysis & $\begin{array}{l}\text { The liquid } \\
\text { color }\end{array}$ \\
\hline $1 \sim 10$ & $16.7 \sim 50$ & $\begin{array}{l}\text { steel surface became } \\
\text { black, and had a tight film }\end{array}$ & few white floccules & $\mathrm{Fe}(\mathrm{OH})_{2}$ & $\begin{array}{l}\text { faint } \\
\text { yellow/green }\end{array}$ \\
\hline $1 \sim 10$ & $50 \sim 90.9$ & & none & none & faint yellow \\
\hline $1 \sim 2$ & $90.9 \sim 100$ & & white floccules & $\mathrm{Fe}(\mathrm{OH})_{2}$ & \\
\hline $3 \sim 10$ & $90.9 \sim 95.2$ & steel surface became black & few yellow floccules & $\mathrm{Fe}(\mathrm{OH})_{2} / \mathrm{Fe}(\mathrm{OH})_{3}$ & colorless \\
\hline $3 \sim 10$ & $95.2 \sim 99$ & & $\begin{array}{l}\text { some black and brown } \\
\text { granular }\end{array}$ & $\mathrm{Fe}_{3} \mathrm{O}_{4} 、 \mathrm{Fe}(\mathrm{OH})_{3} 、 \mathrm{Fe}_{2} \mathrm{O}_{3}$ & \\
\hline $3 \sim 10$ & $99 \sim 100$ & & few yellow floccules & $\mathrm{Fe}(\mathrm{OH})_{2} / \mathrm{Fe}(\mathrm{OH})_{3}$ & \\
\hline
\end{tabular}

With the salinity increased while concentration of Clanion was up to $95.2 \sim 99 \%$ the electrochemical corrosion reactions were aggravated with more black or brown granular ferromagnetic precipitation which preliminary analysis were Fe-oxides and $\mathrm{Fe}(\mathrm{OH})_{3}$. As similar to the research by Z. Xia ${ }^{[7]}$ and M. Abdelmoula ${ }^{[8]}$, the pitting corrosion of carbon steel in $\mathrm{NaCl}$ solution using X-ray diffraction found that initially the corrosion products was $\mathrm{Fe}\left(\mathrm{HCO}_{3}\right)_{2}$ membrane with strong adhesion, by time lasting finally $\mathrm{Fe}\left(\mathrm{HCO}_{3}\right)_{2}$ turned into shrinked porous $\mathrm{FeCO}_{3}$ product. The surface which covered by layer of corrosion products could stop the attack by $\mathrm{HCO}_{3}{ }^{-}$ anion, and contacted with bare area with no corrosion products couple corrosion had happened by pitting. $\mathrm{MaO}^{[2]}$ studied anode polarization curve of low carbon steel in solutions involved $\mathrm{Cl}^{-}$and $\mathrm{NaHCO}_{3}$, the results showed that the shape of the curve varied with the concentration of $\mathrm{NaHCO}_{3}$. Take the solution as $0.005 \mathrm{~mol} / \mathrm{L} \mathrm{NaHCO}_{3}{ }^{+} 0.00 \mathrm{l}$ $\mathrm{mol} / \mathrm{L} \mathrm{NaCl}$ for example, the passivating film was destroyed as small amount of $\mathrm{Cl}^{-}$anion added in $\mathrm{NaHCO}_{3}$ solution, and the curve display the active dissolution characteristics that passivation couldn't happen.

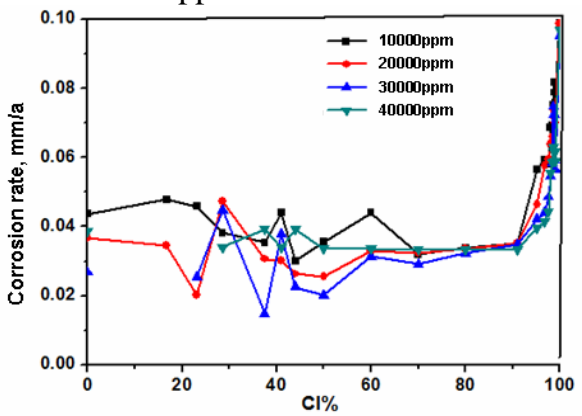

Fig.3 Experimental curve
(2)Data fitting and discussed

On the basis of the least squares principle, the experimental curve can be divided into three parts, namely : (1)the supersaturated zone, (2)the below-concave parabola, (3)exponential increasing part. The fitting curves of corrosion rate and chart board considered by $\mathrm{Cl}^{-}$content as well as salinity were shown in figure 4.

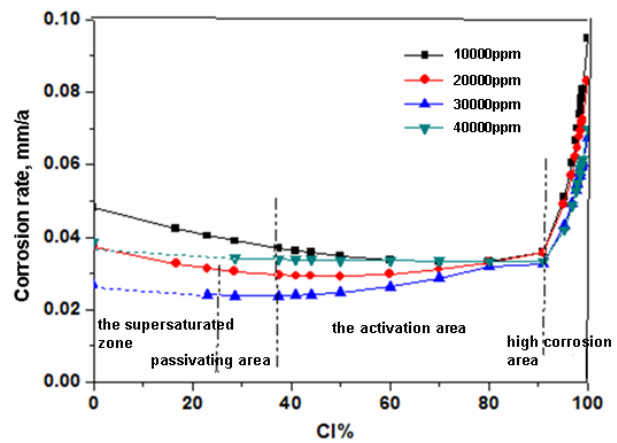

Fig.4 Data fitting curve

Likewise the chart board consist of three parts:(1)passivating area (including the supersaturated zone). When $\mathrm{Cl}^{-}$content was below 37.5\%, the corrosion of the carbon steel was controlled by polarization reaction between $\mathrm{HCO}_{3}{ }^{-}$and $\mathrm{Fe}$, and the dense passivating film generated on the surface had prevented the latter corrosion reaction. While salinity was greater than $20000 \mathrm{mg} / \mathrm{L}$ and $\mathrm{Cl}^{-}$content was lower than 23\%, the solution was super-saturated state.(2)the activation area. When the $\mathrm{Cl}^{-}$content was between $37.5 \%$ and $90.9 \%$, the results of corrosion rate increased slightly followed by solution color turned faint yellow made it clear that passivating film was partly dissolved by $\mathrm{Cl}^{-}$and thus the 
stage could be called $\mathrm{HCO}_{3}^{-}$and $\mathrm{Cl}^{-}$coordinated control area.(3)high corrosion area. When $\mathrm{Cl}^{-}$content was higher than 90.9\%, perforation corrosion caused by $\mathrm{Cl}^{-}$ion was the major factor that the passivating film had been serious destroyed, and corrosion rates rose up exponentially which was called $\mathrm{Cl}^{-}$ perforation control area.

Jing-mao Zhao et al. found that after $\mathrm{Cl}^{-}$joining into $\mathrm{NaHCO}_{3}$ solution passivating film was destroyed as corrosion potential turned negative shift, and local anodic dissolution happened at the active point even corrosion holes appeared on the electrode ${ }^{[5-6]}$. Due to its strong corrosion the $\mathrm{Cl}^{-}$anion could easily penetrate into passivating film that resulted in local damage, then the corrosion micro cell which formed between damaged area and passivating zone had created "large cathode small anode" for the accelerated pitting corrosion. Recent study indicated that the damaged $\mathrm{Fe}\left(\mathrm{CO}_{3}\right)_{2}$ membrane turned to be unstable poor $\mathrm{FeCO}_{3}$ membrane which easily hydrolyzed $\mathrm{Fe}_{3} \mathrm{O}_{4} 、 \mathrm{Fe}_{2} \mathrm{O}_{3}$ and other iron oxides ${ }^{[9]}$. In addition the general white corrosion product $\mathrm{Fe}(\mathrm{OH})_{2}$ demonstrated the cathode $\mathrm{H}_{2} \mathrm{O}$ reduction on metal surface.

\subsection{The influence of salinity on corrosion rate}

As the salinity increased the corrosion rate of carbon steel declined a bit, but the impact on the corrosion was not consistent. When $\mathrm{Cl}^{-} \%$ was in $16.7 \sim 90.9 \%$, with the enlargement of salinity and the concentration of charged ions in solution, the increased solution conductivity accelerated the polarization process, however because of the weak $\mathrm{FeCO}_{3}$ passivating film on steel surface by $\mathrm{HCO}_{3}{ }^{-}$, the higher salinity and stronger polarization reaction, the denser passivating film and lower corrosion rate. When $\mathrm{Cl}^{-} \%$ was in $90.9 \sim 100 \%$, the decreased solution conductivity and strong adsorption by $\mathrm{Cl}^{-}$ restrained the cathode reaction, and thus reduced the steel corrosion rate, as shown in figure 5 .

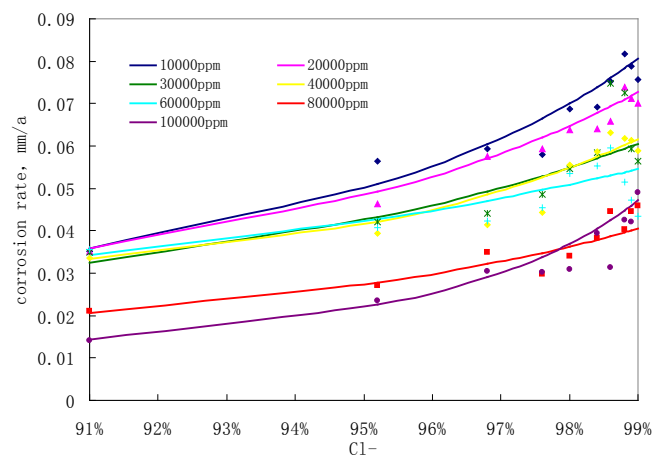

Fig.5 Enlarged drawing of high corrosion area

\section{CONCLUSION}

(1)The anions $\mathrm{Cl}^{-}$and $\mathrm{HCO}_{3}^{-}$had distinct influences on N80 steel corrosion. For $\mathrm{Cl}^{-}$the high corrosion area was at the concentration of $500 \sim 10000 \mathrm{mg} / \mathrm{L}$, then corrosion rate decreased to a certain value by salt effect ; particularly above
$0.02 \mathrm{~mol} / \mathrm{L}_{\mathrm{HCO}_{3}}^{-}$anion play a protective role as the passivating film formed on steel surface.

(2)The corrosion behavior in $\mathrm{NaCl} / \mathrm{NaHCO}_{3}$ solution indicated that the $\mathrm{Cl}^{-} \%$ in region of $16.7 \sim 37.5 \%$ was $\mathrm{HCO}_{3}{ }^{-}$ passivating control area ; in $37.5 \sim 90.9 \%$ was both $\mathrm{HCO}_{3}{ }^{-}$and $\mathrm{Cl}^{-}$coordinated control ; in $90.9 \sim 100 \%$ was $\mathrm{Cl}^{-}$perforation corrosion control area.

(3)The fitted chart board contained salinity and anion content could determine whether the corrosion occur or not, thus may provide theoretical foundation and guidance for the next support design of anticorrosion measures with carbon steel.

\section{REFERENCES}

[1] Jingmao Zhao, Yu Zuo, Anodic polarization behavior of carbon steel in $\mathrm{Na}_{2} \mathrm{CO}_{3}-\mathrm{NaHCO}_{3}$ solution , Journal of Chemical Industry and Engineering $[\mathrm{J}]$ ， 2005， 56 (8) :1526-1529;

[2] X. Mao, X. Liu, R. W. Revie, Pitting corrosion of pipeline steel in dilute bicarbonate solution with chloride ions, Corrosion, 1994, 50(9):651-657.

[3] Qingzhen Du, Shengli Wang, Wei zhang et al. Application of HZ scale and corrosion inhibitor in Huabei Oilfield, Oil Drilling \& Production Technology[J], 2006, 28:39-41;

[4] Qingzhen Du, Gang Xie, Meihang Yang et al. The technology research about reason and mechanism of corrosion in Huabei Oilfield, Journal of Southwest Petroleum University (Science \& Technology) [J], 2013, 35 (3) :142-147;

[5] Jingmao Zhao, Mingguang $\mathrm{Gu}$, Yu Zuo, Influencing factors on corrosion of mild steel in carbon dioxide environment, Journal of Beijing University of Chemical Technology, 2005, 32（5）:71-74.

[6] Jingmao Zhao, Yu Zuo, Anodic polarization behaviors of carbon steel in bicarbonate solution, Electrochemistry, 2005, 11 (1):27-31.

[7] Xia Z, Chou K C et al., Pitting corrosion of carbon steel in CO2-containing NaCl brine. Corrosion, 1989, 45 (7) :636-642;

[8] M. Abdelmoula, Ph. Refait, S.H. Drissi et al. Corrosion electron mössbauer spectroscopy and x-ray diffraction studies of the formation of carbonate-containing green rust one by corrosion of metallic iron in $\mathrm{NaHCO}_{3}$ and $\left(\mathrm{NaHCO}_{3}{ }^{+} \mathrm{NaCl}\right)$ solutions, 1996, 38(4):623-633.

[9] Qianlin Wu, Zhonghua Zhang, Xiaoming Dong et al. Corrosion behavior of low-alloy steel containing 1\% chromium in $\mathrm{CO}_{2}$ environments, 2013, 75:400-408 